\title{
Analisis E-lifestyle dan E-Word Of Mouth terhadap Repurchase Intention Secara Online (Survei pada pelanggan produk fashion online Berrybenka di Fan Page Instagram) \\ Aggi Panigoro ${ }^{1}$, Agus Rahayu ${ }^{2}$ Vanessa Rahayu ${ }^{3}$ \\ Mahasiswa Magister Manajemen \\ Sekolah Pasca Sarjana Universitas Pendidikan Indonesia
}

\begin{abstract}
Abstrak
Fenomena dalam perbelanjaan online membuat para pelaku bisnis memilih sektor e-commerce dan strartup semakin tumbuh di pasaran Indonesia menjadikan peluang bagi para pelaku bisnis untuk menjual produk fashion mereka salah satunya pembuatan e-commerce. Di era digital ini pelanggan lebih mengutamakan kepraktisan dinaungi oleh teknologi tinggi. Tujuan penelitian ini adalah mengukur gambaran dan pengaruh dari $E$-lifestyle dan $E$ Word of mouth terhadap repurchase intention secara online survei pada pelanggan produk online di Berybenka. Peneliti ini menggunakan metode deskriptif dan verifikatif, dimana SEM (Structural equation Modeling) digunakan untuk menganalisis data secara statistika. Unit analisis penelitian adalah pelanggan yang telah berbelanja online fashion di Berrybenka sebanyak 200 responden di fanpage instagram. Hasil penelitian menunjukan repurchase intention akan berpengaruh baik apabila dilihat dari karakteristik E-lifestyle dan pembelian ditinjau dari E-Word of mouth. Hasil penelitian secara keseluruhan menunjukan bahwa terdapat pengaruh yang signifikan dari E-lifestyle dan E-Word of mouth terhadap repurchase intention.
\end{abstract}

Kata kunci : E-lifestyle, E-Word of mouth, repurchase intention

\section{PENDAHULUAN}

Sebagai salah satu permasalah bagi sebuah perusahaan adalah repurchase intention, memiliki persaingan antara perusahaan baik penyedia pelayanan jasa maupun produk yang sedang berkembang di pasar global (Pappas et all, 2014). Repurchase intention sebagai memotivasi konsumen untuk mengulangi perilaku pembelian suatu produk, ditunjukkan dengan penggunaan suatu merek produk secara berkelanjutan (Tsai, 2005).

Beberapa penelitian telah terkonsentrasi pada penentuan variabel anteseden dasar repurchase intention telah dianggap insiden tunggal antara pertemuan kritis dan interaksi memanjang atau hubungan antara variabel-variabel lain (Bitner, et all 1990) (Bolton \& Drew, 1991a,b), (Boulding, et all,1993), , (Liljander \& Strandvik, 1995), (Price, et all,1995), (Grayson \& Ambler, 1999). Konsep dari repurchase intention terdapat di restoran, contoh halnya melalui penelitian dari (Yi\&La, 2004) di restoran Korea dengan responden dilihat dari gende, pekerjaan, umur dan frekuensi kunjungan ke restoran tersebut. Hasil dari penelitian kepuasan memiliki dampak yang signifikan terhadap repurchase intention, sedangkan kualitas pelayanan berpengaruh kurang pada repurchase intention.

Penelitian dari Soderlund,M.,\&Ohman,(2003) menunjukan bahwa pada repurchase intention berasal dari para konsumen atas dorongan para pelaku bisnis.
Terdapat juga pada industri produk olahraga badminton di tahun 2015 penelitian dilakukan Chiu\&Won,(2016) di Taipe Taiwan dengan responden komunitas olahraga badminton yang menggunakan racket. Dihasilkan brand commitmen memiliki pengaruh positif pada repurchase intention Artinya, konsumen dengan komitmen yang tinggi untuk merek tertentu memiliki tingkat lebih tinggi dari niat untuk berulang kali membeli produk bermerek sama dan mengembangkan hubungan jangka panjang.

Di Indonesia penelitian Yulianti,et all,(2014) dilakukan di Bali pada industri Retail Circle K yang membuka gerainya 24 jam. Responden terdiri dari pengunjung yang serta berbelanja minimal tiga kali dalam sebulan.

penelitian tentang repurchase intention mengacu pada pembelian di toko online (Chen \& Jiang, 2013)(Rezaei \& Amin, 2013)(Aren, Güzel, Kabadayı, \& Alpkan, 2013)(Gounaris \& Boukis, 2013)(Muhammad, 2013)(Pappas et al., 2014)(Razak, Marimuthu, Omar, \& Mamat, 2014)(Cho, 2015)(Bao, 2015)(Li, 2016)(Chou \& $\mathrm{Hsu}$, 2016) karena repurchase intention mengacu kepada peluang subjektif pengulangan konsumen mengajari suatu toko online dan merupakan penentu utama dari kegiatan pembelian (Wu, Chen, Chen, \& Cheng, 2014). Perbelanjaan di online, berdasarkan pertumbuhan internet ini, muncul dengan cara yang cepat, sejumlah peluang besar untuk pemasok online 
telah meningkatkan dalam rangka menciptakan dan melestarikan interaksi dengan pelanggan (Pappas et al., 2014).

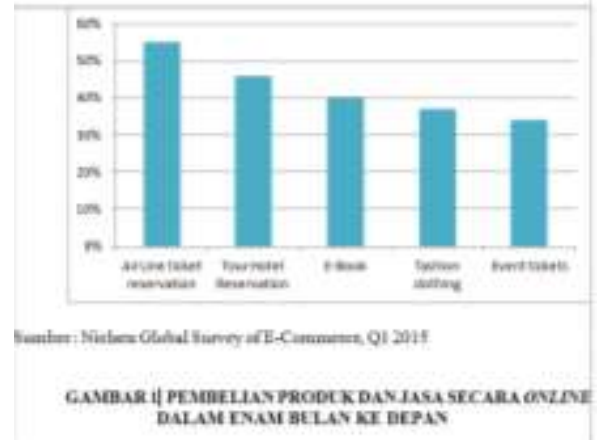

Hasil survei Nielsen mengungkapkan bahwa jSekitar setengah dari konsumen Indonesia berencana untuk membeli secara online tiket pesawat (55\%) serta melakukan pemesanan hotel dan biro perjalanan (46\%) dalam enam bulan ke depan. Empat dari sepuluh konsumen (40\%) berencana untuk membeli buku elektronik. Hampir empat dari sepuluh konsumen berencana untuk membeli fesyen dan pakaian (37\%), dan lebih dari sepertiga konsumen merencanakan untuk membeli tiket acara (34\%) secara online (nielson.com diakses 29 Desember 2016).

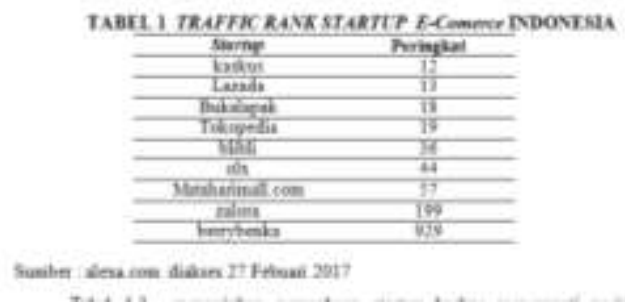

Tabel 1 menunjukan perusahaan startup kaskus menempati posisi pertama sebagai startup ecommerce yang secara regional di Indonesia dengan peringkat 12 . Kaskus sebenarnya adalah sebuah forum online.

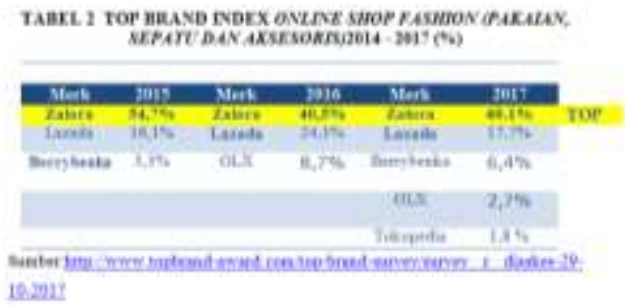

Kriteria top didasarkan pada survei yang dilakukan oleh Frontier Consulting Group. Untuk kategori online shop pakaian dan aksesoris dari tahun 2015 sampai 2017 zalora masih berada diperingkat pertama dengan pengaruh 40,1\% di tahun 2017. Untuk diposisi terakhir ditahun 2015 dan 2016 OLXdan Tokopedia ditahun 2017 tokopedia dan blibli peringkat dibawah karena spesifik merek bukan hanya fashion online melainkan toko online serba ada.

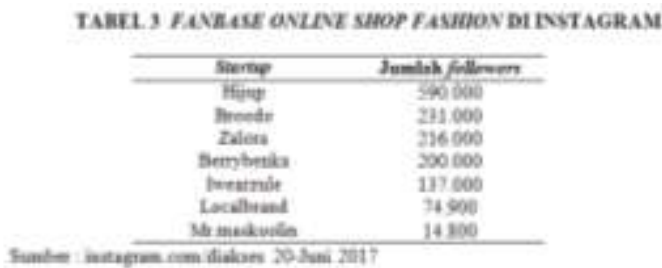

Jumlah follower paling banyak dalam fanbase kategori fashion online adalah Hijup dengan jumlah followers 590.000. HIJUP.com adalah Islamic fashion ecommerce pertama di dunia yang didirikan pada tahun 2011. Dengan konsep online mall, HIJUP.com menyediakan berbagai macam produk terbaik karya designer fashion muslimah Indonesia. Broodo menduduki dengan jumlah follower kedua terbesar di Indonesia 231.000 , brodoo dikhusukan untuk produk sepatu. Peringkat ketiga Zalora, merupakan fashion online E-commercce terbesar dengan jumlah fanbase 216.000. berrybenka dengan jumlah fanbase 200.000 followers

Tujuan pembelian ulang ini dipengaruhi oleh beberapa faktor, seperti: brand preference, perceived value, perceived quality dan perceived price (Tsai, 2005). Repurchase intention terdapat tiga dimensi yang membuat pelanggan membeli ulang produk diantaranya yaitu niat pembelian ulang produk yang sama, kemungkinan membeli kembali pembelian ulang produk yang sama dan komunikasi informasi yang diarahkan pada konsumen lain tentang produk dan jasa penjual (Sahin et.al 2012).

Saat ini memperberdayakan konsumen untuk melakukan berbagi informasi yang saat ini dapat dengan mudah diakses dan sebagian besar konsumen dapat memberitahukan pengalamannya melalui internet, disebutkan juga ketika terjadi pertukaran informasi melalui electronic word-of-mouth, konsumen akan melakukan evaluasi terhadap produk. (J. Q. Zhang,et al, 2010)

Kemajuan teknologi informasi dan komunikasi (TIK) yang luar biasa, pakar industri telah meminta penelitian dari perspektif e-lifestyle untuk mengeksplorasi bagaimana pengaruhnya terhadap penggunaan teknologi layanan atau produk berbasis teknologi (Chen and He, 2006; (Yu, 2011)

Berrybenka merupakan perusahaan starup berkonsep fashion online shop dilihat data sekunder bahwa berrybenka berada diposis rendah. Pemilihan mediasosial isntagram sebagai perhitungan populasi serta sampling karena menurut Asosiasi Pengguna Jasa Internet Indonesia dan top rank Alexa saat ini 
instagram paling banyak pengguna aktif di Indonesia dan Dunia.

\section{KERANGKA PENELITIAN \& HIPOTESIS}

\section{Repurchase Intention}

Hawkins, (2016:6) mendefinisikan perilaku konsumen adalah studi tentang individu, kelompok, atau organisasi dan proses yang konsumen gunakan untuk memilih dan menggunakan produk dan jasa atau proses ini untuk memuaskan kebutuhan konsumen. Individu mengembangkan konsep diri (pandangan mereka tentang diri mereka sendiri) dan gaya hidup, selanjutnya (bagaimana mereka hidup) berdasarkan berbagai pengaruh internal (terutama psikologis dan fisik) dan eksternal (terutama sosiologis dan demografis).

Repurchase intention memiliki tujuan untuk tingkat motivasional seorang konsumen untuk mengulangi perilaku pembelian suatu produk, yang salah satunya ditunjukkan dengan penggunaan brand suatu produk secara berkelanjutan (Chang \& Wildt, 1994).

Penilaian individu tentang pembelian kembali melalui layanan yang ditunjuk sebagai produk atau jasa untuk mempertimbangkan dan menggunakan kembali serta memiliki faktor untuk mengarah ke profitabilitas pembisnis dan perusahaan (Noyan \& Simsek, 2012). ketika konsumen melakukan kegiatan pembelian kembali untuk kedua kali atau lebih, alasan pembelian kembali terutama dipicu oleh pengalaman konsumen terhadap produk atau jasa (Heiller et all, 2003).

Repurchase intention memiliki tiga tingkatan Heiller et al., (2003)yaitu 1) continue to purchase yang dimana konsumen akan terus membeli setidaknya sama jumlahnya, 2) All things considered memiliki pertimbangan ketika konsumen mau membeli produk yang akan memberikan kontribusi kedepannya, 3) continue to condition and contribute kondisi keuangan yang tepat akan membuat konsumen terus berkontribusi untuk pembelian sesuatu produk yang sama.
Repurchase intention memiliki tujuan untuk tingkat motivasional seorang konsumen untuk mengulangi perilaku pembelian suatu produk, yang salah satunya ditunjukkan dengan penggunaan brand suatu produk secara berkelanjutan (Chang \& Wildt, 1994). (Y. Zhang et al., 2011) ada tiga tingkatan dan pengukuran pada repurchase intention melalui pembelanjaan online yaitu : Kemungkinan peluang untuk pembelian secara online dari vendor yang sama - Pembelian ulang dalam jangka menengah dan pembeliang ulang dalam jangka panjang di masa depan. Berhenti dalam pembelian ulang melalui vendor yang sama.

\section{E-Word of Mouth}

Maksud dari word of mouth sumber informasi yang paling penting ketika konsumen membuat keputusan pembelian (Yayli \& Bayram, 2009). Word of mouth tidak hanya dilakukan perorangan namun bisa dalam bentuk apa saja termasuk internet yang disebut dengan electronic word of mouth (e-WOM) (Jalilvand \& Samiei, 2012).

Electronic word of mouth suatu pernyataan posistif dan negatif yang dibuat oleh konsumen aktual, potential serta konsumen sebelumnya mengenai produk atau perusahaan dimana informasi ini tersedia bagi konsumen ataupun institusi melalui media internet (Hennig-Thurau,et al. 2004).

Salah satu sumber informasi yang paling penting ketika konsumen membuat keputusan pembelian Dengan ketersediaan alat online interaktif melalui internet, pengguna mendorong inovasi tingkat yang lebih tinggi (Prahalad amp; Krishnan, 2008). Dari situs menuju ke forum menuju ke tweet kebanyakan komunikasi adalah mode dominan untuk bersosialisasi dan telah menjadi perbincangan baru di dunia media sosial seperti facebook (Sharma \& Pandey, 2011).

Dimensi E-WOM Platform Assistance / Penyedia Bantuan, yaitu frekuensi konsumen dalam mengunjungi serta menuliskan opininya. Concern for Other / Perhatian terhadap konsumen lain, yaitu keinginan membantu orang lain dalam pengambilan keputusan pembelian. Economic Intensive / Penghargaan Ekonomi, yaitu pendorong perilaku manusiasebagai tanda penghargaan dari pemberi 
hadiah. Helping Company / Membantu perusahaan, yaitu keinginan membantu perusahaan sebagai imbalan terhadap perusahaan karena telah puas terhadap produk maupun jasanya. Expressing Positive Emotions / Mengekspresikan pengalaman positif, yaitu mengungkapkan perasaan positif serta peningkatan diri setelah memakai produk/jasa. Venting Negative Feelings / Melampiaskan perasaan negatif, yaitu berbagi pengalaman yang tidak menyenangkan untuk mengurangi ketidakpuasan. Social Benefits / Keuntungan sosial, yaitu anggapan menerima manfaat sosial dari anggota komunitas. Advice Seeking / Mencari nasihat, yaitu harapan mendapatkan pemecahan masalah setelah adanya interaksi dengan orang lain (Hennig-Thurau,et al. 2004).

\section{E-lifestyle}

E-lifestyle telah dinyatakan berbeda dengan gaya hidup tradisional karena gaya hidup tradisional dikonsepkan mungkin tidak memadai dalam menjelaskan gaya hidup, sedangkan E-lifestyle dikonsepkan dimulai dengan beraktivitas, ketertarikan kepada sesuatu hal dan pendapat seseorang menggunakan era digital (Hoon, 2002). Konsumen elifestyle juga diprediksi dan penilaian oleh konstruksi psikologis dan sosiologis (Yu, 2011) E-lifestyle, dalam penelitian ( Kaynak and Kara 2001;Yu, 2011 ;), sebagai pola dalam yang orang tinggal dan menghabiskan waktu dan uang mereka melalui internet dan elektronik. Salah satu gaya hidup inovatif memungkinkan produk dan layanan yang dikaitkan dengan teknologi dan informasi (Chanaron, 2013). Oleh karena itu, banyak manajer tingkat tinggi berpendapat bahwa penelitian dari perspektif $e$ lifestyle dapat memberi pemasar dasar yang berguna untuk pemasaran, dan merancang layanan untuk pelanggan.

Terdapat tujuh dimensi e-lifestyle dalam penelitian (Pandey \& Chawla, 2014) yaitu :

1. E-enjoyment, berkaitan dengan kenyamanan saat berbelanja online di rumah.

2. E-distrust, Berkaitan dengan tidak adanya kepercayaan terkait dengan privasi dan keamanan informasi yang dimiliki oleh para vendor internet.

3. E-offers, Berkaitan dengan kepercayaan tentang penawarkan, kualitas dan seleksi yang lebih baik di internet jika dibandingkan dengan toko lokal.

4. E-self-inefficacy, Berkaitan dengan rasa takut tidak mengetahui bagaimana menggunakan internet, karena tidak ada teman yang memberi informasi tentang vendor online shop.

5. E-logistic concern, kekhawatiran berkaitan dengan ketakutan akan masalah proses pengembalian barang dan kebijakan vendor internet.

6. E-negative beliefs, berkaitan dengan pendapat untuk tidak berbelanja barang mahal di internet dan pembelian yang tidak perlu didorong oleh iklan dan promosi oleh internet marketer.

7. Love brick and mortar, berkaitan dengan pengalaman belanja toko tradisional dibandingkan dengan toko online.

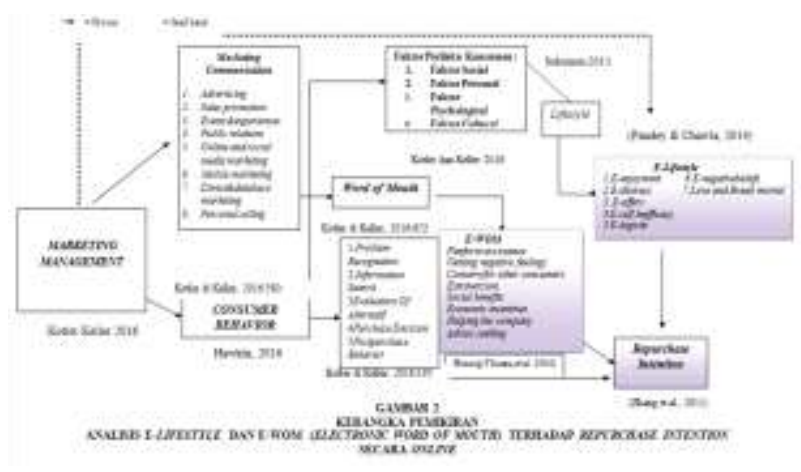

1. Terdapat pengaruh E-lifestyle dengan indikator: E-enjoyment,E-negativebeliefs, Edistrust , E-offers, E-self-inefficacy, E-logistic dan Love danBreak mortal dan Electronic Word of Mouth dengan indikator Platform assistance, Venting negative feelings, Concern for other consumers, Extraversion, Social benefits, Economic incentives, Helping the company dan Advice seeking terhadap repurchase intention terdiri dari online repeat order, timeless repeat order dan switch to competitor

\section{METODE PENELITIAN}


Penelitian ini menguji bagaimana E-Lifestyle dan E-Word of Mouth terhadap repurchase intention Selanjutnya, penelitian ini akan meneliti satu variabel independent, variabel dependent dan satu variabel intervening yang diteliti yaitu E-Lifestyle sebagai $\mathrm{X}_{1}$ ,dengan sub variable: E-enjoyment,E-negativebeliefs, E-distrust , E-offers, E-self-inefficacy, E-logistic dan Love and Break mortal dan Electronic Word of Mouth sebagai $\mathrm{X}_{2}$ dengan indikator Platform assistance, Venting negative feelings, Concern for other consumers, Extraversion, Social benefits, Economic incentives, Helping the company dan Advice seeking. Kemudian yang menjadi di variabel terikat (dependent variable) adalah $\mathrm{Y}$ repurchase intention. Responden dalam penelitian ini adalah fanbase instagram berrybenka melalui follower .Penelitian ini dilakukan dalam kurun waktu kurang dari satu tahun yaitu dari bulan Januari hingga Juli 2017, maka metode yang digunakan adalah cross sectional method, yaitu metode penelitian dengan cara mempelajari objek dalam satu kurun waktu tertentu/tidak berkesinambungan dalam jangka waktu panjang.

Berdasarkan pengertian populasi tersebut, populasi penelitian ini adalah fanbase follower instragram berrybenka 200.000 digunakan dalam uji hipotesis yang menggunakan model persamaan struktural atau Structural Equation Model (SEM), dikarenakan dari segi metodologi SEM memainkan berbagai peran, diantaranya adalah sebagai sistem persamaan simultan, analisis kausal linier, analisis lintasan (path analysis), analysis of covariance structure, dan model persamaan structural.

Berdasarkan penentuan sample dengan menggunakan rumus teknik Slovin maka hasil sampel sebesar 192 Menurut (Surakhman, 1998) penamabahan jumlah sampel agar lebih matematis perlu dilakukan agar sample yang digunakan representative, maka sampel dibulatkan menjadi 200 sampel.

Pengujian hipotesis dilakukan dengan menggunakan teknik SEM. Karena tujuan pertama dari penelitian adalah untuk menguji teori, maka teknik analisis yang digunakan adalah SEM berbasis covariance (covariance based SEM), yakni pendekatan SEM yang menggunakan tools AMOS. Data primer yang diperoleh dari pengumpulan data yang dilakukan, dimasukkan ke dalam sebuah file exel yang dimasukan melalui IBM SPSS AMOS 23 terlebih dahulu sebelum dianalisis lebih lanjut. Tools yang digunakan dalam penelitian ini untuk memasukkan data dalam format input IBM SPSS 23 .

4. HASIL DAN PEMBAHASAN

\section{Rekapitulasi E-lifestyle}

Secara keseluruhan variabel E-lifestyle (X1) yang terdiri dari E-enjoyment, E-negativebeliefs, E-distrust, E-offers, E-self-inefficacy, E-logistic dan Love and Break mortal. dapat dapat diketahui kedudukannya berdasarkan skor yang didapat dari rekapitulasi data, dimana nilai-nilai tersebut dibandingkan dengan kriteria skor standar yang didapatkan melalui perhitungan skor ideal (kriterium) dengan skor terkecil,

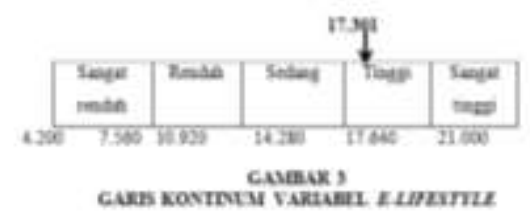

Nilai kontinum E-lifestyle yaitu dengan perolehan nilai 17.301 atau dengan persentase sebesar $82,38 \%$ sesuai dengan data penelitian yaitu termasuk dalam kategori tinggi artinya melalui hasil pengukuran diketahui bahwa dalam variabel E-lifestyle yang diteliti dimensi E-enjoyment, E-negativebeliefs, E-distrust , Eoffers, E-self-inefficacy, E-logistic dan Love and brick telah berjalan dengan baik dalam penelitian ini.

\section{Rekapitulasi E-Word Of Mouth}

Secara keseluruhan variabel $E$-word of mouth (X2) yang terdiri dari Platform assistance, Venting negative feelings, Concern for other consumers, Extraversion, Social benefits, Economic incentives, Helping the company dan Advice seeking

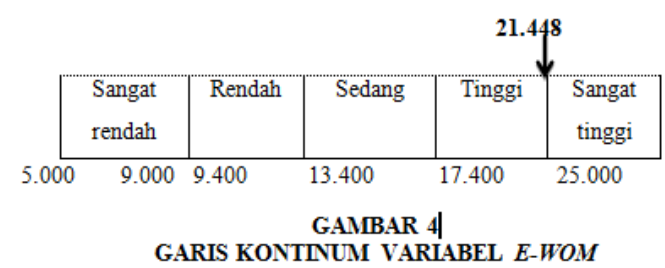

nilai kontinum E-word of mouth yaitu dengan perolehan nilai 21.448 atau dengan persentase sebesar $85,78 \%$ sesuai dengan data penelitian yaitu termasuk dalam kategori tinggi artinya melalui hasil pengukuran diketahui bahwa dalam variabel E-word of mouth (X2) yang terdiri dari Platform assistance, Venting negative feelings, Concern for other consumers, Extraversion, Social benefits, Economic incentives, Helping the company dan Advice seeking telah berjalan dengan baik dalam penelitian ini.

\section{Rekapitulasi Repurchase intention}

Secara keseluruhan variabel repurchase intention (Y) yang terdiri dari online repurchase, timeless repeat 
order dan switch repurchase intention dapat dapat diketahui kedudukannya berdasarkan skor yang didapat dari rekapitulasi data,

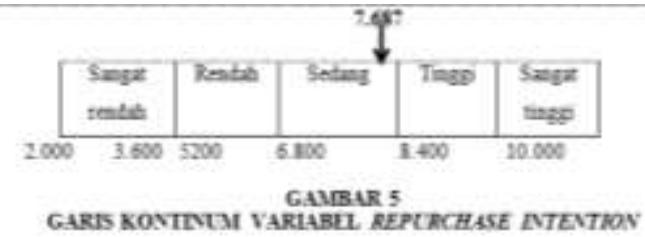

nilai kontinum E-word of mouth yaitu dengan perolehan nilai 7.687 atau dengan persentase sebesar $76,87 \%$ sesuai dengan data penelitian yaitu termasuk dalam kategori tinggi artinya melalui hasil pengukuran diketahui bahwa dalam variabel repurchase intention (Y) yang terdiri dari online repurchase, timeless repeat order dan switch repurchase intention telah berjalan dengan baik dalam penelitian ini.

\section{Pembahasan hipotesis}

Uji normalitas ini dapat dilihat pada nilai nilai Critical Ratio (CR) dari skewness dan kurtosisnya. Jika nilai CR antara rentang - 2.58 sampai dengan 2.58 ( \pm 2.58 ) pada tingkat singnifikansi $1 \%(0.01)$,

\section{Normalitas data}

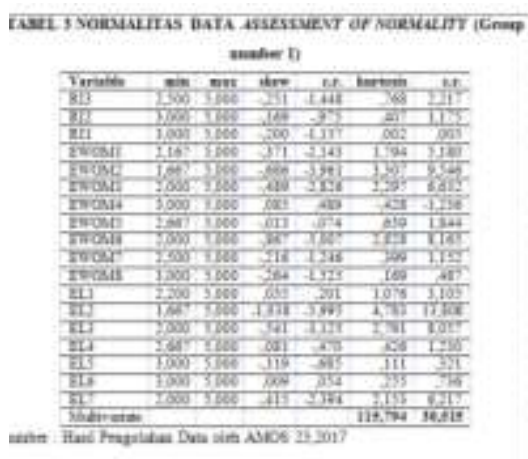

Berdasarkan pengolahan data tabel 3 dapat dilihat uji asumsi statistika menunjukan secara multivariat data set sampel berdistribusi normal $(c r>2,58)$.

III. Pengujian model penelitian

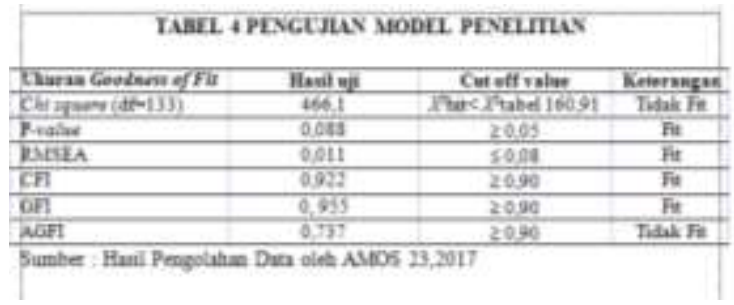

Uji kesesuaian SEM di atas menghasilkan $\mathrm{df}=133$ dengan nilai Chi squere 466,1 > Chi squere yakni 160,91, dan nilai $P$ value 0,088 mengidentisifikasikan model fit . nilai RSMEA 0,011 $\leq 0,08$ berarti model fit dengan data. Selanjutnya pada indeks kecocokan CFI sebesar 0,922 dan GFI 0,955 lebih besar dari kriteria yaitu sebesar $\geq 0,90$. Sehingga keseluruhan model fit data tetapi AGFI kurang dari $\geq 0,90$ yaitu 0,737. Menurut Malhotra (2010:737) menggunakan paling sedikit 1 ukuran bersifat baik misalnya (CFI,GFI) bersifat absolut baik. Untuk 1 ukuran bersifat buruk misalkan (Chi squere, RMSR, RMSEA) dan 1 ukuran bersifat komparatif misalnya (NFI, NNFI, VFI, TLI, RNI). Terlihat seluruh ukuran Goodness of Fit lebih besar dari cut-off value, maka dapat disimpulkan bahwa model penelitian pada SEM sudah fit.

\section{Model structural}

Analisis model struktural berhubungan dengan evaluasi terhadap parameter yang menunjukan hubungan yang kausal atau pengaruh satu variabel laten terhadap variabel laten lainnya. Uji kecocokan untuk memeriksa tingkat kecocokan antara data model, validitas dan realibilitas model pengukuran dan signifikan koefisien dari model struktural. Berikut ini disajikan gambar parameter estimasi standardized loading factor berikut .

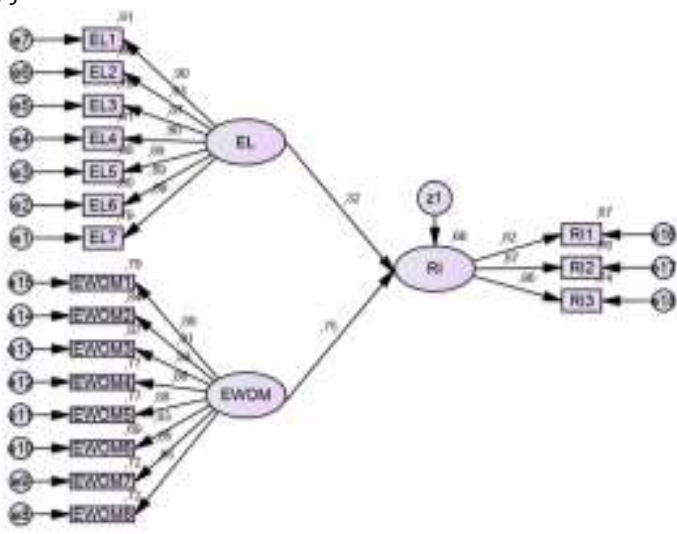

Sumber : Hasil Pengolahan Data oleh AMOS 23,2017

GAMBAR 6 MODEL STRUKTURAL PADA STRUCTURAL EQUATION MODEL KESELURUHAN

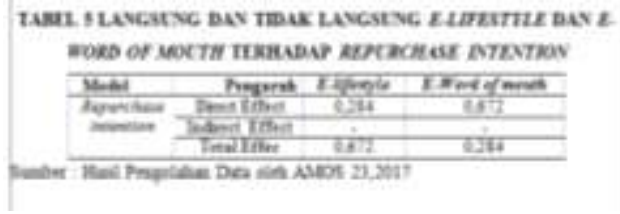

Berdasarkan tabel di atas dapat dilihat bahwa pengaruh yang paling tinggi terhadap Repurchase Intention adalah E-Word of mouth sebesar 0,672. 
Sedangkan untuk variabel lebih kecil adalah E-lifestyle sebesar 0,284

\section{KESIMPULAN}

1. Gambaran E-lifestyle dan E-Word of Mouth serta Repurchase intention secara online dinilai tinggi oleh para pelanggan yang telah berbelanja di berrybenka, hal ini terbukti dari penerapan strategi E-lifestyle dan E-Word of Mouth sehingga terciptanya Repurchase intention terhadap produk yang ditawarkan oleh berrybenka.

2. Pengaruh E-lifestyle dan E-Word of Mouth terhadap Repurchase intention berpengaruh positif signifikan. Dimensi yang mendapatkan penilaian tertinggi berdasarkan persepsi responden adalah E-enjoyment. Karena semakin tinggi tingkat E-enjoyment semakin tinggi pula pembelian ulang. Sedangkan tanggapan yang terendah adalah pada dimensi E-logistic.perilaku Pengaruh E-Word of Mouth terhadap Repurchase intention berpengaruh positif signifikan. Dimensi yang mendapatkan penilaian tertinggi berdasarkan persepsi responden adalah dimensi Platform assistance Sedangkan tanggapan yang terendah adalah pada dimensi Advice seeking. Pelanggan mempercayai sesuatu penanganan terhadap perbelanjaan online ketika pelanggan merasa hasil dari perbelanjaan online kurang ekspetasi tidak sesuai keinginan dan ingin mengeluh komentarnya kedalam review kolom atau menghubungi call center berrybenka melalui email banyak dilakukan pelanggan yang kecewa. Dengan meningkatkan fast respone solution membuat pelanggan puas atas kinerja dari berrybenka ketika mendapat pelanggan yang kecewa dengan kedatangan barang yang tidak sesuai. Bahwa Platform assistance menunjukan konsumen sangat didorong oleh kecenderungan mengunjungi aplikasi ecommerce seperti berrybenka.
6. REKOMENDASI

1. Responden melalui dimensi E-lifestyle yang memiliki nilai paling tinggi E-enjoyment dengan adanya hasil tersebut peneliti merekomendasikan agar perusahaan lebih memperbaiki kualitas di aplikasi smartphone lebih responsif dalam menggunakan aplikasi berrybenka. karena bentuk kenyamanan paling diutamakan pelanggan agar mempermudah dalam pembelian produk fashion di berrybenka

2. Responden melalui dimensi E-logistic merekomendasikan agar pengantaran dan pengembalian produk produk fashion di berrybenka lebih ditingkatkan lagi misalnkan dengan cara memberikan biaya pengantaran kurir gratis apabila melalui sistem drop di gerai atau pop up store di kota-kota besar di Indonesia yang telah disediakan oleh berrybenka.

3. Dimensi Platform assistance dengan adanya hasil tersebut peneliti merekomendasikan agar perusahaan lebih meningkatkan kepedulian cepat tanggap terhadap keluhan mulai dari pembelian produk sampai pengiriman produk ke tempat pelanggan yang dituju, agar tidak ada kesan negatif ketika menuliskan review dan komentar di kolom komentar mediasosial. Menambahkan kolom review dan komentar di aplikasi berrybenka. Agar pengguna pelanggan lainnya menjadi tempat bagi para penikmat internet, untuk mencari dan mengumpulkan informasi tentang pertemuan, penilaian dan pandangan konsumen lain, agar memperkuat brand dari berrybenka dikenal oleh konsumen online

4. Dimensi Economic Intensive lebih mendekatkan vendor berrybenka dengan pelanggan misalkan membuat sistem member yang sering atau telah berbelanja di berrybenka akan mendapatkan potongan dan harga promosi. Ketika produk fashion berrybenka tidak ada yang terjual bisa menggunakan produk tersebut dengan menambahkan bonus ketika pembelian produk. 
5. Dimensi online repurchase meningkatkan kualitas dan kuantitas produk fashion berrybenka mulai dari produk sampai hubungan relasi dengan pelanggan agar pelanggan bisa membeli ulang kembali produk fashion.

6. Saran bagi penelitian selanjutnya adalah diharapkan dapat melakukan penelitian secara mendalam mengenai e-lifestyle e-word of mouth, dan repurchase intention secara online, karena penelitian tersebut dapat menjadi stimulus bagi berrybenka untuk meningkatkan kegiatan komunikasi pemasaran sebagai salah satu faktor yang mempengaruhi peningkatan pembelian ualng secara online.

\section{DAFTAR PUSTAKA}

Aren, S., Güzel, M., Kabadayı, E., \& Alpkan, L. (2013). Factors Affecting Repurchase Intention to Shop at the Same Website. Procedia - Social and Behavioral Sciences, 99, 536-544. http://doi.org/10.1016/j.sbspro.2013.10.523

Bao, J. (2015). The Impacts of E-service Quality on Customers ' Repurchase Intention in Platform Online Retailing : An Empirical Investigation.

Bitner, M.J., Booms, B.M. and Tetreault, M.S. (1990).pdf. (1990).

Bolton, R. N., \& Drew, J. H. (1991). No Title, 17, 375384.

Boulding, W., Kalra, A., Staelin, R., \& Zeithaml, V. A. (1993). Journal of Marketing Research, 30(1), 727.

Chang, T.-Z., \& Wildt, A. R. (1994). Price, Product Information, and Purchase Intention: An Empirical Study. Journal of the Academy of Marketing Science, 22(1), 16-27. http://doi.org/10.1177/0092070394221002

Chen, Y. F., \& Jiang, J. H. (2013). Effects Of Classical and Operant Conditioning On Online Consumer Purchase and Repurchase Intention. In Proceedings of 8th Asian Business Research Conference, Bangkok, Thailand., (April).

Cho, Y. K. (2015). Creating customer repurchase intention in Internet retailing: The effects of multiple service events and product type.
Journal of Retailing and Consumer Services, 22, 213-222.

http://doi.org/10.1016/j.jretconser.2014.11.00 2

Chou, S. W., \& Hsu, C. S. (2016). Understanding online repurchase intention: social exchange theory and shopping habit. Information Systems and EBusiness Management, 14(1), 19-45. http://doi.org/10.1007/s10257-015-0272-9

Gounaris, S., \& Boukis, A. (2013). The role of employee job satisfaction in strengthening customer repurchase intentions. Journal of Services Marketing, 27(4), 322-333. http://doi.org/10.1108/08876041311330799

Grayson, K., \& Ambler, T. I. M. (1999). The Dark Side of Long-Term Relationships in Marketing Services, 36(1), 132-141.

Hennig-Thurau, T., Gwinner, K. P., Walsh, G., \& Gremler, D. D. (2004). Electronic word-of-mouth via consumer-opinion platforms: What motivates consumers to articulate themselves on the Internet? Journal of Interactive Marketing, 18(1), 38-52. http://doi.org/10.1002/dir.10073

Jalilvand, M. R., \& Samiei, N. (2012). The effect of electronic word of mouth on brand image and purchase intention. Marketing Intelligence \& Planning, 30(4), 460-476. http://doi.org/10.1108/02634501011078138

Li, Y. (2016). Empirical Study of Influential Factors of Online Customers' Repurchase Intention. iBusiness, 8(3), 48-60. http://doi.org/10.4236/ib.2016.83006

Liljander, V., \& Strandvik, T. (1995). The Nature of Customer Relationships in Services, 4, 1-35.

Muhammad, F. (2013). Factors Affecting the Repurachse Online Shopping Intention. AU-GSB E-JOURNAL.

Noyan, F., \& Simsek, G. G. (2012). A Partial Least Squares Path Model of Repurchase Intention of Supermarket Customers. Procedia - Social and Behavioral Sciences, 62, 921-926. http://doi.org/10.1016/j.sbspro.2012.09.156

Pappas, I. O., Pateli, A. G., Giannakos, M. N., \& Chrissikopoulos, V. (2014). Moderating effects 
of online shopping experience on customer satisfaction and repurchase intentions. International Journal of Retail \& Distribution Management, 42(3), 187-204. http://doi.org/10.1108/IJRDM-03-2012-0034

Phillip, K., Gus, M., Rodney, a, \& John, a. (2003). Customer repurchase intention. European Journal of Marketing, 37(11), 1762-1800. http://doi.org/10.1108/03090560310495456

Price, L. L., Arnould, E. J., Tierney, P., Price, L. L., \& Arnould, E. J. (1995). Service Extremes: Managing Encounters and Assessing Provider Performance to, 59(2), 83-97.

Razak, N. S. A., Marimuthu, M., Omar, A., \& Mamat, M. (2014). Trust and Repurchase Intention on Online Tourism Services among Malaysian Consumers. Procedia - Social and Behavioral Sciences, 130, 577-582. http://doi.org/10.1016/j.sbspro.2014.04.067

Rezaei, S., \& Amin, M. (2013). Exploring online repurchase behavioural intention of university students in Malaysia. Journal for Global Business Advancement, 6(2), 92-119. http://doi.org/10.1504/JGBA.2013.053561

Şahin, A., Zehir, C., \& Kitapçı, H. (2012). The effects of brand experience and service quality on repurchase intention: The role of brand relationship quality, 6(November), 1119011201. http://doi.org/10.5897/AJBM11.2164

Sharma, R. S., \& Pandey, T. (2011). The impact of electronic word-of-mouth in the distribution of digital goods. Webology, Vol. 8, Article 84. Retrieved from http://www.webology.org/2011/v8n1/a84.htm I

Soderlund,M.,\&Ohman, N. (2003). Behavioral intentions in satisfaction research revisited. Journal of Customer Satisfaction, Dissatisfaction and Complaining Behavior.pdf. SWEDEN: journal of consumer satisfaction, dissatisfaction and complaing behavior.

Surakhman, W. (1998). Pengatar Penelitian IImiah Dasar. Bandung: Tarsito.

Tsai, S. P. (2005). Utility, cultural symbolism and emotion: A comprehensive model of brand purchase value. International Journal of Research in Marketing, 22(3), 277-291. http://doi.org/10.1016/j.ijresmar.2004.11.002

Weisheng Chiu and Doyeon Won. (2016). Consumerbrand relationships in sports products and repurchase intention An application of the investment model. http://doi.org/10.1108/IJSMS-08-2016-013

Wu, L. Y., Chen, K. Y., Chen, P. Y., \& Cheng, S. L. (2014). Perceived value, transaction cost, and repurchase-intention in online shopping: A relational exchange perspective. Journal of Business Research, 67(1), 2768-2776. http://doi.org/10.1016/j.jbusres.2012.09.007

Yayli, a P. a, \& Bayram, I. M. (2009). eWOM: THE EFFECTS OF ONLINE CONSUMER REVIEWS ON PURCHASING DECISION OF ELECTRONIC GOODS. Marketingtrendscongresscom. http://doi.org/10.1504/IJIMA.2012.044958

Yi, Y., \& La, S. (2004). What Influences the Relationship between Customer Satisfaction and Repurchase Intention? Investigating the Effects of Adjusted Expectations and Customer Loyalty. Psychology and Marketing, 21(5), 351-373. http://doi.org/10.1002/mar.20009

$\mathrm{Yu}, \mathrm{C}$. (2011). Construction and validation of an elifestyle instrument. Internet Research, 21(3), 214-235. http://doi.org/10.1108/10662241111139282

Yulianti, N. M. D. R., Suprarti, N. W. S., \& Yasa, N. N. K. (2014). Pengaruh Citra Toko terhadap Kepuasan Pelanggan dan Niat Beli Ulang pada Circle K di Kota Denpasar. Jurnal Manajemen Strategi Bisnis Dan Kewirausahaan, 8(1), 36-44.

Zhang, J. Q., Craciun, G., \& Shin, D. (2010). When does electronic word-of-mouth matter? A study of consumer product reviews. Journal of Business Research, 63(12), 1336-1341. http://doi.org/10.1016/j.jbusres.2009.12.011

Zhang, Y., Fang, Y., Wei, K. K., Ramsey, E., McCole, P., \& Chen, H. (2011). Repurchase intention in B2C e-commerce - A relationship quality perspective. Information and Management, 48(6), 192-200. http://doi.org/10.1016/j.im.2011.05.003

www.nielson.com $/ 2017$ www.instagram.com-2017 www.topbrandindex.com/2017 